\title{
A Experiência Integrada da Lomba do Pinheiro: 0 diálogo territorial em Porto Alegre para além do Orçamento Participativo
}

The Integrated Lomba do Pinheiro Experiment: Territorial Dialogue in Porto Alegre beyond Participatory Budgeting

L'Expérience Intégrée de la Lomba do Pinheiro: le dialogue territorial à Porto Alegre par delà le Budget Participatif

Cleia Beatriz Hauschild de Oliveira e Andrea Oberrather

\section{OpenEdition}

\section{Journals}

Edição electrónica

URL: http://journals.openedition.org/rccs/4475

DOI: $10.4000 /$ rccs. 4475

ISSN: 2182-7435

\section{Editora}

Centro de Estudos Sociais da Universidade de Coimbra

\section{Edição impressa}

Data de publição: 1 Dezembro 2010

Paginação: 255-274

ISSN: 0254-1106

Refêrencia eletrónica

Cleia Beatriz Hauschild de Oliveira e Andrea Oberrather, « A Experiência Integrada da Lomba do Pinheiro: O diálogo territorial em Porto Alegre para além do Orçamento Participativo », Revista Crítica de Ciências Sociais [Online], 91 | 2010, colocado online no dia 01 dezembro 2012, criado a 19 abril 2019. URL : http://journals.openedition.org/rccs/4475 ; DOI : 10.4000/rccs.4475 


\section{CLEIA BEATRIZ H. OLIVEIRA ANDREA OBERRATHER}

\section{A Experiência Integrada da Lomba do Pinheiro: O diálogo territorial em Porto Alegre para além do Orçamento Participativo}

O município de Porto Alegre tem experimentado processos participativos que vão além da abertura do aparelho do Estado à participação direta da população nas decisões dos investimentos públicos proporcionada pelo Orçamento Participativo. Através dos chamados "Congressos da Cidade", a população pode contribuir para a modificação dos instrumentos de planejamento urbano físico-territorial.

O bairro Lomba do Pinheiro, cuja região é marcada pela presença de importantes recursos naturais, tem a oportunidade de conquistar melhorias urbanas através de legislação moderna capaz de garantir a realização de obras e transformações físicas e socioambientais. Neste território teve início em março de 1998 o chamado Projeto Integrado de Desenvolvimento Sustentável da Lomba do Pinheiro, que permite articular ações de distintos organismos municipais tendo em vista produzir lotes de interesse social em terrenos aptos para usos urbanos, assim como equipamentos comunitários. Esta ação é mais que um Plano, é uma intenção forte de transformação através do projeto urbano, redesenho, parceria e monitoramento do desenvolvimento, em que a participação faz a diferença.

Palavras-chave: investimento público; Orçamento Participativo (OP); planeamento urbano; processos participativos.

\section{Introdução}

Desde 1994, o município de Porto Alegre tem experimentado processos participativos que vão além da abertura do aparelho do Estado à participação direta da população nas decisões a respeito dos objetivos dos investimentos públicos proporcionada pelo Orçamento Participativo (que incorpora a decisão da população na discussão sobre parte dos gastos do município à qual pertence). Esses processos iniciam uma ampla discussão pública através dos chamados "Congressos da Cidade", de forma a contribuir para a modificação dos instrumentos de planejamento urbano físico-territorial, 
com ações de médio e longo prazos como o PDDUA, o Plano de Diretor de Desenvolvimento Urbano e Ambiental. ${ }^{1}$

A partir da revisão do Plano Diretor vigente até 1999 surgem novos instrumentos, além da capacitação dos técnicos da Secretaria de Planejamento Municipal. A revisão - que resultou na aprovação de um novo plano diretor - incluiu ao mesmo tempo os instrumentos de redesenho territorial e as instituições de gestão progressiva das transformações, como o CMDUA, o Conselho Municipal Desenvolvimento Urbano Ambiental (Oliveira e Barcellos, 1993; Allegretti, 2002; Krafta, 1993), proporcionando um "alinhamento" da organização territorial do planejamento com aquela do Orçamento Participativo, com o intuito de favorecer o intercâmbio produtivo entre as diferentes instâncias de participação da cidade.

No processo "constituinte" que se desencadeou a partir da decisão de procurar uma maior integração entre dispositivos participativos com horizontes de médio e de longo prazo, várias formas de consulta dos cidadãos foram sendo integradas como "obrigatórias" dentro do processo administrativo municipal, com o objetivo de dar voz a todos os habitantes dos diferentes territórios, independentemente dos seus direitos formais. Nos níveis mais baixos - como o das Unidades de Estruturação Urbana (UEUs) - estes processos de diálogo social têm tido um valor apenas consultivo, sendo realizados de forma rápida e difusa para não tornar os percursos decisórios pesados demais. Mas as indicações deles resultantes foram sendo registradas pelos fóruns populares das várias Regiões Administrativas e pelo CMDUA, dotados de um caráter "deliberante" na construção dos processos de planejamento.

Por outro lado, os Planos de Ação Regionais (PARs) adquiriram no início do milênio uma tarefa de "lugares densos" e "operacionais" do processo geral de planejamento, conforme regrado no artigo 43 da Lei Complemen$\operatorname{tar} 434 / 99$, que sancionou a entrada em vigor do novo PDDUA e os definiu como conjuntos de ações que visam promover o desenvolvimento de cada região a partir das análises das suas singularidades, dialogando com as diretrizes gerais propostas pela cidade. A redação destes planos, de fato, vai além da simples elaboração detalhada do PDDUA, para tornar-se instrumento indispensável na proposta de melhorias, adequações e reformulações através de uma "dinâmica continuada e sistemática". Estes planos foram concebidos também como espaços de atribuição de competências a técnicos e cidadãos, estes últimos organizados em comissões de acompanhamento e controle das obras no território, em diálogo com os processos ativados em escala local através do Orçamento Participativo.

${ }^{1}$ LC 434/99 - PDDUA - Plano Diretor de Desenvolvimento Urbano Ambiental. 
A redação destes planos foi-se dando lentamente, seguindo os princípios da "investigação-ação" previstos no PDDUA, a partir das experimentações já começadas em algumas zonas da cidade, com o intuito de construir uma 'metodologia de trabalho' capaz de respeitar aquele princípio inspirador das políticas cidadãs que Fedozzi (2000:59) tem definido como "a prática como critério de verdade". Segundo esse princípio, "trabalhar através de projetos é como criar precedentes jurídicos em positivo" com base nos quais é possível atualizar e revisar o planejamento (De Oliveira apud Allegretti, 2002: 287).

A Lomba do Pinheiro é uma das áreas onde, desde março de 1998, foi sendo conduzido um projeto-piloto experimental, designado Projeto Integrado de Desenvolvimento Sustentável da Lomba do Pinheiro, que tornou possível articular ações de distintos organismos municipais para executar intervenções que produzirão lotes de interesse social em terrenos aptos para usos urbanos. Com efeito, "o Projeto Integrado de Desenvolvimento Sustentável da Lomba do Pinheiro, depois de anos de planejamento participativo com a comunidade local, culminou nas propostas de desenvolvimento social, econômico e territorial e os mecanismos de execução" (De Oliveira, Pegoraro apud Rojas, 2009: 94)

O Projeto Integrado em questão é portanto mais que um Plano, é uma intenção forte de transformação através do projeto urbano, de redesenho, de parceria e monitoramento do desenvolvimento, em que a participação faz a diferença. Os mais de 63000 habitantes, espalhados numa área "suburbana", marcada pela presença de importantes recursos naturais, têm a oportunidade de conquistar melhorias urbanas, através do trabalho participativo desenvolvido com base na necessidade de uma nova representação dos territórios locais que compõem a região.

Hoje, significativo avanço já aconteceu, não só do ponto de vista da escolha de necessidades de obras que ocorrem com recursos públicos, mas em especial no efetivo interesse de empreendedores que já estão construindo novos lotes urbanizados, assim como casas e equipamentos comunitários, tais como escolas, praças e equipamentos de saúde.

Acrescentamos a perspectiva da realização de grandes transformações urbanas ligadas à Copa do Mundo de Futebol de 2014. Nas vésperas da abertura de novo debate, que ocorrerá a partir do V Congresso da Cidade (realizado de março a novembro de 2011 e coordenado por um comitê gestor reunindo administração pública e sociedade civil), pode ser interessante reconstruir alguns dos processos de planejamento que estão transformando esta área.

Por outro lado, o Plano Integrado da Lomba representa uma qualificação das necessidades do bairro, pois visa conjugar ações de melhoria no atendimento à saúde, ao provimento de vagas escolares e à construção 
de parques e praças destinados à recreação, além de promover a regularização fundiária e urbanística e contribuir para a produção de habitações populares. Através desta integração já se obteve a construção de inúmeros equipamentos de ensino e saúde, um dos mais importantes desafios para a transformação sustentável de Porto Alegre. Além disso, o caso da Lomba do Pinheiro representa uma experiência onde o reconhecimento dos valores sociais e ambientais da região aparece como componente central do planejamento, filtrada por uma vertente de forte valorização da participação dos moradores nas ações de planejamento local.

O lugar escolhido para aplicar esta experiência-piloto teve como critério de seleção as suas especificidades urbanísticas, suas características físicas capazes de impor uma atitude vigorosa para preservar o ambiente natural e ao mesmo tempo estimular cenários econômicos favoráveis. Nesta perspectiva, a região da Lomba do Pinheiro foi objeto de estudo aprofundado antes de 1998, tendo em vista incorporar na prática e na legislação urbanística padrões diferenciados adequados e compatíveis com as características de um território economicamente carente e fisicamente desorganizado, onde se tornava necessário induzir, através de uma conjugação das forças do mercado imobiliário formal e informal, alternativas de reversão do processo perverso de exclusão socioterritorial.

Em junho de 2009, foi aprovada na Câmara de Vereadores de Porto Alegre legislação local em matéria de urbanismo que visa não só a promoção de parcerias entre ações públicas e iniciativa privada na produção de habitação direcionada à população de baixa renda, mas possibilita também a construção de uma agenda diferenciada para o poder público local, que tradicionalmente trata estas questões da informalidade com programas curativos, que no final não atacam a origem do problema.

Esta nova legislação toma forma no marco da aplicação da Lei Federal denominada de Estatuto da Cidade, ${ }^{2}$ mas também em instrumentos que fazem parte integrante do quadro criado pelo novo Plano Diretor de Porto Alegre, ${ }^{3}$ como a chamada Lei Complementar do Urbanizador Social, ${ }^{4}$ que visa proporcionar um diálogo entre as instituições locais e os diferentes atores que no passado eram responsáveis pelo crescimento espontâneo de muitos bairros residenciais. O intuito é reduzir a informalidade urbana e, ao mesmo tempo, proporcionar lotes urbanizados com custos menores e qualidade mais elevada.

\footnotetext{
${ }^{2}$ EC- Lei 10.257 de 9 de outubro de 2001.

3 LC 434/99 - PDDUA - Plano Diretor de Desenvolvimento Urbano Ambiental.

${ }^{4}$ Lei 9162/2003.
} 
O presente artigo descreve a experiência-piloto da Lomba do Pinheiro nesta perspectiva, deixando aberta uma pergunta central, que só poderá ser respondida pelos futuros desenvolvimentos: até que ponto o poder público tem capacidade de exercer o seu papel de promotor do desenvolvimento e garantir no tempo a permanência dos resultados obtidos através da parceria entre investimentos públicos e privados?

\section{Contexto da cidade e da Região Lomba do Pinheiro}

Porto Alegre, capital do Rio Grande do Sul, tem 470,25 km² de área, sendo esta limitada a sul e a oeste pelo rio Guaíba e a norte e a leste por municípios integrantes da região metropolitana. É o principal município da homônima Região Metropolitana (RMPA) ${ }^{5}$ e hospeda mais de 1,5 milhões de habitantes. ${ }^{6}$ A sua população está mais concentrada na metade norte, onde também se encontram os grandes equipamentos urbanos de escala metropolitana, e para a metade sul possui propriedades rurais, com áreas que ainda mantêm as suas características naturais.

A peculiaridade da região da Lomba do Pinheiro é ser uma área desvinculada da malha urbana contínua e compacta, com superfície de aproximadamente 3214 hectares. Constitui-se numa parcela do território municipal que se destaca pela presença de valores naturais significativos para a cidade, com influência na Região Metropolitana. Esta zona tem sido ao longo dos anos uma alternativa "popular" para a residência, acabando por ser marcada por um conjunto de assentamentos habitacionais bastante desorganizados, que apresentam ausência ou precariedade no atendimento de serviços públicos, possuem sérios problemas de infraestrutura e saneamento básico e constituem situações de risco, além de uma intensa degradação ambiental.

A morfologia urbana da região é constituída por lotes urbanos convencionais, com pátios onde se plantam árvores e se criam animais domésticos e com edificações, na sua maioria, constituídas por casas unifamiliares e comércio de abastecimento local. Hoje existem na Lomba mais de 50 assentamentos irregulares ou clandestinos, que representam aproximadamente $6 \%$ dos existentes em toda a cidade. Praticamente todas as ocupações urbanas na Lomba do Pinheiro têm algum tipo de irregularidade urbanística e fundiária, sendo que as conseqüências deste elevado número de ocupações carentes de infraestrutura urbana são sentidas por todos os

\footnotetext{
${ }^{5}$ RMPA - Região Metropolitana de Porto Alegre, composta por 31 municípios e com 3,974 milhões de habitantes.

${ }^{6}$ Fonte: Prefeitura Municipal de Porto Alegre.
} 


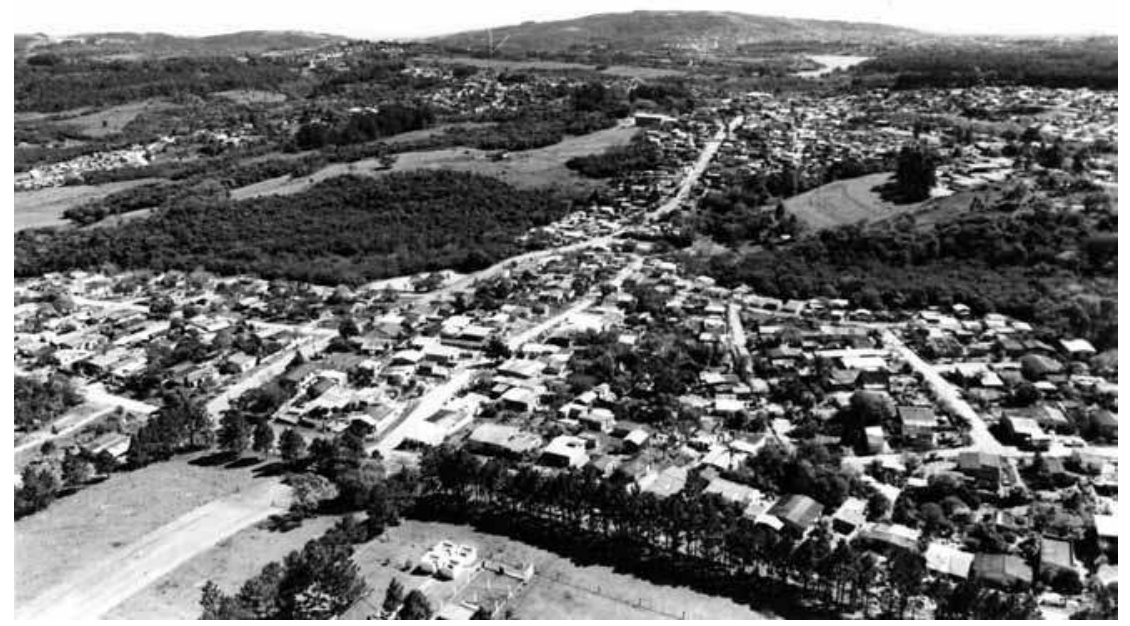

Lomba do Pinheiro - Áreas ocupadas e vazias?

moradores. Dos 63970 habitantes da Lomba ${ }^{8}$ a esmagadora maioria tem uma média de 2,92 salários mínimos por chefe de domicílio.

O Plano Diretor anterior, vigente desde 1979, de certa forma impedia ocupações habitacionais com padrões convencionais (Liedke e Ferretti Brum, 1993). Este impedimento legal contribuiu para a instalação dos loteamentos à margem do controle público, sem o devido atendimento das exigências para padrões urbanísticos determinados, como largura de vias, reserva de área para equipamentos públicos de educação, saúde e lazer, bem como a preservação dos bens naturais existentes. A degradação ambiental foi um dos efeitos mais evidentes deste processo, pois as edificações se estendem até junto aos arroios gerando, além da poluição, o desmatamento, que provoca risco de deslizamento e inundação para as moradias, que são por sua vez atingidas pela água nas épocas de chuva intensa.

A comunidade está hoje organizada em diversas associações de moradores, vinculadas às vilas (bairros espontâneos ou semiespontâneos) onde moram, e tem uma significativa trajetória de participação nas conquistas infraestruturais da região. Através da mobilização comunitária, nos últimos

\footnotetext{
${ }^{7}$ As fotografias apresentadas neste artigo são da autoria da Comunicação Social da Prefeitura Municipal de Porto Alegre/RS.

${ }^{8}$ De acordo com o Censo 2000 - Instituto Brasileiro de Geografia e Estatística, atualizado a cada 10 anos, com projeção realizada pela Secretaria do Planejamento Municipal da Prefeitura de Porto Alegre para 2006.
} 


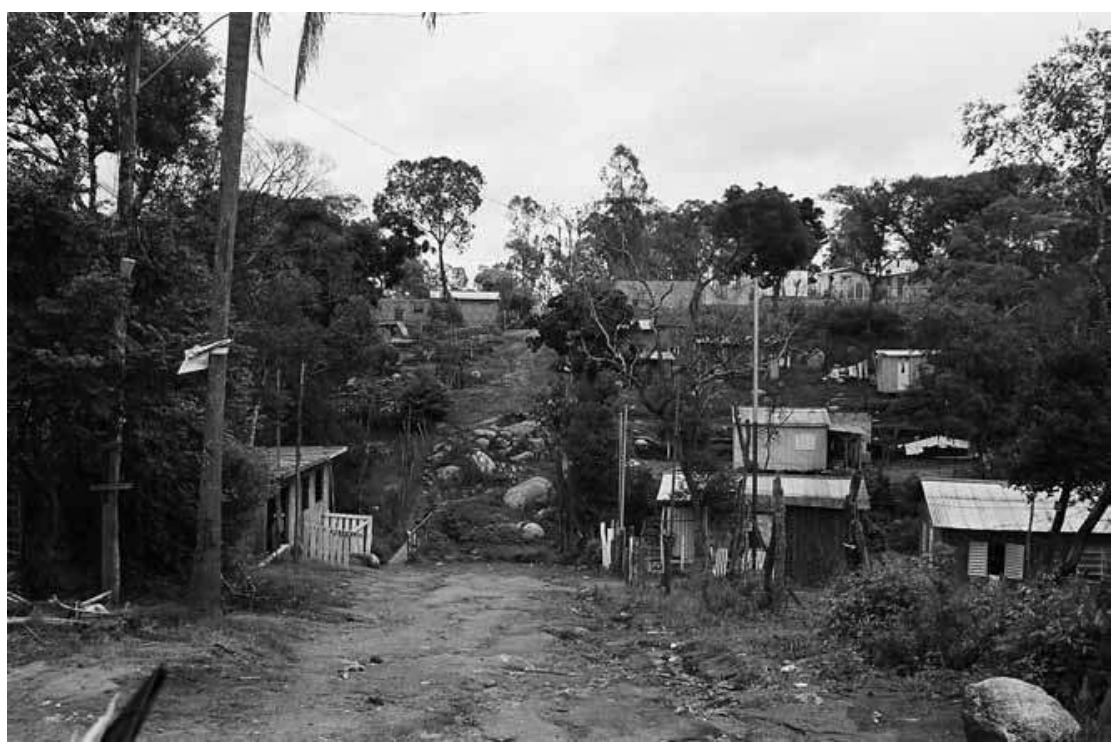

Ocupações irregulares com carência de infraestrutura

20 anos a população local conseguiu a atenção do poder público para a implantação de redes e serviços essenciais com atuação muito ativa no Orçamento Participativo, conquistando urbanização e melhorias dentro das vilas, assim como na integralidade da região.

A falta de infraestrutura revelou-se como uma conseqüência natural da ação prevalente dos loteadores clandestinos, que foram demarcando e vendendo os lotes sem qualquer compromisso com a execução de obras de instalação de redes de água, esgotos, iluminação predial e pública, pavimentação e arborização, entre outras (Silva, 1993). A progressiva implantação destas redes e serviços pelo poder público, feita principalmente a partir do orçamento público (e no caso de Porto Alegre através do orçamento participativo), acabou sempre ficando aquém da expectativa e das próprias necessidades dos moradores. Apesar disto, a Lomba do Pinheiro atualmente ainda apresenta uma significativa concentração de glebas vazias, representando um potencial de ocupação urbana para o futuro. De toda a região considerada no estudo ambiental que deu origem ao projeto-piloto, em torno de $50 \%$ da área se encontra hoje vazia e aproximadamente $28 \%$ foi considerada apta para ocupação urbana.

Neste momento observam-se duas tendências claras para a ocupação destes vazios. Por um lado, existem iniciativas a favor da chamada "habitação de interesse social”. Vários empreendimentos já estão comercializando lotes urbanizados regulares, para atender uma demanda habitacional reprimida 
na cidade, mantendo o perfil existente dos moradores da região. Por outro lado, a região está também atraindo empreendimentos para novos grupos sociais, nomeadamente de classe média, que têm buscado melhor qualidade de vida em zonas mais periféricas da cidade, onde as condições naturais podem ser mais integradas às moradias.

Nesta perspectiva, o Projeto Integrado Lomba do Pinheiro implementa vários instrumentos do PDDUA, respeitando as suas estratégias principais, mas declinando-as através de um processo participativo que articule e descentralize o planejamento das ações visadas à promoção do desenvolvimento urbano.

\section{Instrumentos e participação}

O PDDUA de Porto Alegre, que apresenta sete estratégias (AA.VV., 1998), entre as quais merece destacar a que se refere à chamada "Estratégia de Produção da Cidade" (que inclui ações baseadas numa leitura pragmática do território e das maneiras com ele forja as suas transformações, independentemente da vontade dos legisladores e das administrações públicas), propicia que o Poder Público seja o agente promotor do desenvolvimento, como se verifica no enunciado do artigo 21 do PDDUA:

Estratégia de Produção da Cidade tem como objetivo a capacitação do Município para a promoção do seu desenvolvimento através de um conjunto de ações políticas e instrumentos de gerenciamento do solo urbano que envolvem a diversidade dos agentes produtores da cidade e incorporam as oportunidades empresariais aos interesses do desenvolvimento urbano como um todo.

Também estimula, entre outros programas, o que segue:

I - Programa de Projetos Especiais, que busca promover intervenções que, pela multiplicidade de agentes envolvidos no seu processo de produção ou por suas especificidades ou localização, necessitam critérios especiais e passam por acordos programáticos estabelecidos com o Poder Público, tendo como referência os padrões definidos no Plano Regulador;

II - Programa de Habitação de Interesse Social, que propõe a implementação de ações, projetos e procedimentos que incidam no processo de ocupação informal do solo urbano. ${ }^{9}$

\footnotetext{
${ }_{9}$ Definição conforme artigo 23 da Lei Complementar 434/99-PDDUA.
} 
Dentro deste contexto está inserido o Projeto Integrado da Lomba do Pinheiro, o qual visa a melhor execução da política urbana, adotando novas diretrizes de cooperação entre os diferentes níveis administrativos e políticos, a iniciativa privada e os demais setores da sociedade no processo de urbanização, além de ordenar o uso do solo urbano e compatibilizar os recursos do Orçamento Participativo para obras viáveis que, em conjunto, possam configurar uma "estratégia em rede". Assim, a experiência-piloto busca o estabelecimento de uma metodologia de trabalho projetual como instrumento de promoção de um planejamento mais gerencial e participativo, dentro de uma visão menos "normativa" que a dos Planos Diretores Municipais das duas décadas anteriores, os quais nem sequer reconheciam a existência de favelas e loteamentos irregulares já consolidados há muitos anos (Comas Dias, 1993).

A gestão do projeto foi pensada como um processo que tem continuidade no tempo, sendo que etapas subseqüentes dependem diretamente de um bom planejamento das atividades e dos recursos disponíveis, para não somente tornar factíveis as propostas, como também para ter atratividade e capacidade de relacionar-se com a realidade, com os problemas sociais vivenciados no território e os interesses políticos.

Já em 1998 a promoção de inúmeras apresentações do Projeto Integrado, com ênfase nos seus objetivos, etapas e conteúdos, abriu o diálogo; debates e oficinas de trabalho procuraram não só propiciar o encontro dos profissionais com os agentes de cooperação, as organizações de moradores, as lideranças, mas, especialmente, capacitar e preparar os agentes públicos no seu papel de promotores do desenvolvimento. Esta ação diferenciada do poder público, moderadamente documentada na literatura (Allegretti, 2005), veio a ser complementada por novos e importantes instrumentos de política urbana e habitacional, como o denominado de Urbanizador Social, já indicado no PDDUA de 1993. Conforme bem descrito em Damásio (2006), trata-se de uma medida inovadora que veio a incentivar um cadastramento no Município de uma série de empreendedores imobiliários que tinham atuado - até 2003 - fora ou às margens de leis, planos e regulamentos, com vista a realizar empreendimentos de interesse social em áreas identificadas pelas autoridades municipais. Assim, o Urbanizador Social veio constituir-se em um instrumento que facilita a produção e implementação de parcelamento do solo ou edificações destinadas a suprir a demanda habitacional prioritária, ou seja, com renda correspondente até 5 salários mínimos. Também poderá atender as famílias de outras camadas de renda que façam parte do mercado informal de terras, em uma clara tentativa de diminuir o espaço de atuação das forças informais de promoção do acesso à terra urbana. 
Uma das dificuldades de implementar a medida, quase única no Brasil, do Urbanizador Social foi a necessidade de articulá-lo com outros instrumentos de política urbana, como o Solo Criado, as Áreas Urbanas de Ocupação Prioritária, as Áreas Especiais de Interesse Social, a captação de mais-valias, etc. Por esta razão, de 2003 até 2005 um Convênio entre a Prefeitura Municipal de Porto Alegre e o Lincoln Institute of Land Policy foi desencadeando um estudo de áreas-piloto, para tornar o instrumento real e comprovar a sua eficácia. Estes estudos levaram à indicação da região da Lomba como a área mais apropriada para o desenvolvimento de um projeto-piloto sobre o Urbanizador Social, que pudesse juntar-se às outras experimentações já em curso.

\section{Nova forma de gestão pública}

Conforme já realçado, o Projeto Integrado da Lomba do Pinheiro foi lançado, oficialmente, em agosto de 1999, com a instalação de escritórios em três escolas municipais da região. O objetivo desta medida foi o de aproximar a atuação do Município dos cidadãos e aprofundar os conhecimentos da realidade local. A proposta - inovadora em Porto Alegre - propiciou a contribuição efetiva dos moradores, a partir do efeito multiplicador gerado pelo envolvimento das crianças que habitavam na área. Esta ação propiciou a construção de uma consciência coletiva sobre os sérios conflitos entre urbanização e preservação dos elementos naturais existentes, que representam importantes valores agregados do território. Através de técnicas inovadoras (como o uso do teatro de rua), também alertou para as necessidades de estruturação e mobilidade urbana, de qualificação ambiental, de produção de novas habitações e de viabilização dos recursos financeiros necessários para aplicar na recuperação e estruturação da região.

Nesta perspectiva, a primeira fase do Projeto da Lomba teve como objetivo geral identificar oportunidades de desenvolvimento que resolvessem os conflitos de urbanização, compatibilizando-os com a preservação dos bens naturais, além de garantir o atendimento da demanda habitacional reprimida e a criação de postos de trabalho e de programas de geração de renda. O amplo caminho percorrido sucessivamente poderia ser dividido em três fases:

$\left.1^{a}\right)$ Trabalho interno de capacitação técnica e conhecimento da região, através da implementação de novos escritórios do projeto em escolas municipais e realização de várias reuniões com os atores locais na área de estudo, para a construção dos objetivos mais detalhados a serem desenvolvidos.

$\left.2^{a}\right)$ Elaboração do diagnóstico dos meios natural e construído, envolvendo a Universidade Federal do Rio Grande do Sul, órgãos estaduais e 
municipais, além da forte participação dos moradores (através da criação do Grupo de Planejamento Local) na elaboração do Diagnóstico Rápido Participativo.

$3^{\circ}$ ) Elaboração e aprovação na Câmara de Vereadores da lei de Operação Urbana Consorciada para a Lomba do Pinheiro.

Durante a realização do "Diagnóstico do Meio Natural", a Universidade Federal do Rio Grande do Sul (UFRGS), através de técnicos do Centro de Ecologia, do Instituto de Geociências e do Instituto de Pesquisas Hidráulicas, definiu o grau de aptidão natural ao uso e ocupação do solo na região da Lomba do Pinheiro e orientou a equipe de técnicos da Prefeitura de Porto Alegre para realizar um "Diagnóstico do Meio Construído", de acordo com os parâmetros até ali adotados. Esta aptidão resultou da análise do cruzamento de um conjunto de dados sobre os recursos hídricos, as áreas de preservação permanente, a valoração da cobertura vegetal e do meio biótico, a geologia, a geotécnica, o escoamento superficial e a hidrogeologia. A avaliação das características do meio construído objetivou determinar o grau de urbanização das diversas vilas espontâneas e loteamentos irregulares e clandestinos já implantados no território. Através de uma mesma metodologia e da definição de critérios de atendimento, o percurso participativo atribuiu um valor relativo para cada rede e serviço, classificado por eixos temáticos denominados de Infraestrutura Urbana, Estruturação Urbana e Perfil Socioeconômico. ${ }^{10}$ Estes valores foram relacionados entre si por tema, de forma a estabelecer-se uma nota ${ }^{11}$ ou um índice que permitisse a comparação direta de uma área com outra, determinando a qualidade de urbanização de cada uma.

Para uma real participação foi fundamental a criação do chamado GPL - Grupo de Planejamento Local -, composto por representantes de organismos públicos e privados e membros da comunidade local. Esta iniciativa significou um grande avanço em 2003/2004, não só na etapa de conhecimento da realidade, mas em especial no chamado Diagnóstico Rápido Participativo, que recolheu a visão local dos participantes do Grupo, com classificação e priorização de problemas, assim como propostas de solução.

O conjunto dos diferentes estudos parciais até aqui citados resultou no chamado Estudo Ambiental, que, tendo como base um aprofundado

\footnotetext{
${ }^{10}$ Infraestrutura urbana diz respeito às redes básicas de água, energia elétrica, esgoto pluvial e cloacal e redes complementares como transporte coletivo, coleta de lixo e pavimentação. Estruturação urbana diz respeito aos equipamentos complementares à habitação, tais como escolas, creches, postos de saúde e praças. O perfil socioeconômico utiliza os dados do Censo do IBGE (2000) relativos à população, renda, grau de instrução e domicílios.

${ }_{11}$ Os conjuntos de notas referentes à infraestrutura, estruturação urbana e perfil socioeconômico estão expressas nos mapas, publicados em Bases para o Plano de Desenvolvimento Local - Volume 1.
} 
conhecimento da realidade, levou à finalização do Diagnóstico Integrado que, por sua vez, não só avaliou a situação existente quanto à infraestrutura e às suas carências, mas principalmente identificou propostas capazes de resolver os conflitos locais, criando, ao mesmo tempo, oportunidades de desenvolvimento, além de uma forte integração com os agentes sociais e políticos que pudessem contribuir para o seu desenvolvimento. Utilizando-se diferentes ferramentas, foi possível identificar as diversas relações existentes entre os sistemas que interferem no meio natural e construído e foram priorizadas as soluções para os problemas apontados por moradores entrevistados que, após a realização de uma oficina especial com a comunidade, foram sendo organizados conforme as áreas ${ }^{12}$ física, social e econômica, buscando maneiras de viabilizar as ações, algumas destas já conquistadas e executadas.

No decorrer do Projeto, após 2006, definiu-se um modelo de desenvolvimento urbano, baseado em metas e diretrizes para intervenção na região, conforme quatro princípios de ação:

- regular o uso do solo propiciando a ocupação dos vazios urbanos, com vista à contenção da especulação imobiliária e da destruição do patrimônio ambiental;

- aperfeiçoar o processo de planejamento urbano a partir do desenvolvimento econômico local, fortalecendo a participação dos cidadãos em busca de parcerias e formas colegiadas de atuação;

- avançar na descentralização das políticas ambientais através de um planejamento estratégico, que conciliasse os diferentes interesses;

- promover mudanças nos padrões de produção e consumo do ambiente local.

\section{Orçamento Participativo e planejamento local}

A partir de 2000, o Fórum permanente criado na Lomba do Pinheiro tem orientado visitas coletivas, "Oficinas de mapas" e módulos de observações empíricas do território, que têm proporcionado a reconstrução consensual da origem e da evolução da cidade e da própria parte habitada da Lomba, através da leitura e da atualização de textos como os cadernos históricos "Memórias dos bairros"' (realizados pelo município nos anos anteriores em muitos dos 82 bairros da cidade) e de seminários com peritos capazes de ajudar a colocar a região no contexto urbano geral e aprofundar o seu aporte específico ao "todo". Visitas de técnicos, grupos escolares da Lomba

\footnotetext{
${ }_{12}$ Área Física - implementar Programa de Educação Ambiental; Área Social - implantação do Posto de Saúde 24 horas; Área Econômica - implantar Centro de Formação e Promoção dos assuntos econômicos na região.
} 
e demais habitantes ao Museu da Cidade e análises coletivas do "Atlas Ambiental de Porto Alegre", instrumento interativo a cargo da Prefeitura e da Universidade Federal do Rio Grande do Sul (Menegat, 1998), enriqueceram as metodologias tendo em vista a construção de "consciência do território" e o reforço da "pertença".

Também a criação do jornal Construindo a Lomba do futuro procurou divulgar para um público mais amplo o que foi aprendido pelos habitantes que aceitaram participar nas várias atividades promovidas pela Prefeitura; novos módulos de formação foram sendo ativados para ajudar a compreender a história do planejamento em Porto Alegre e em que medida um plano de urbanismo influencia a vida dos habitantes. Isto foi considerado necessário, dado que a falta de compreensão deste aspecto tinha sido avaliada como razão da escassa participação na construção do PDDUA entre 1994 e 1998.

Foi neste quadro que entre dezembro de 2000 e Janeiro de 2001 o Fórum Regional da Região de Planejamento n. ${ }^{\circ} 7$ Lomba-Partenon identificou as demandas a serem inseridas na elaboração do Plano Plurianual 2002-2005, reunindo-se pela primeira vez com os Fóruns dos Delegados Regionais do Orçamento Participativo.

O sistema do Orçamento Participativo (OP) implantado em Porto Alegre a partir de 1989, que já se tinha tornado referência mundial em participação popular em meados dos anos 90, desenvolveu um papel importante no Projeto-Piloto da Lomba. Conforme mostrado nos Planos de Investimentos entre 1998 e 2010, uma grande parte da infraestruturação nos loteamentos clandestinos e irregulares da Lomba passou pelas decisões do OP, tais como pavimentação de ruas, implantação de redes de água e de esgoto sanitário, construção de escolas infantis, postos de saúde, atendimento 24 horas de médicos especializados. Estas obras foram realizadas com o total de recursos destinados para a região através da divisão dos investimentos públicos na cidade.

Assim, através do $\mathrm{OP}$ as comunidades organizadas fizeram aprovar várias de suas demandas nas assembléias regionais e deliberaram as prioridades e ações a serem realizadas a cada gestão orçamentária anual. Isto produziu um conhecimento empírico da região bastante abrangente, capaz de identificar as suas principais necessidades nas questões de redes e serviços.

O Projeto Integrado tinha como premissa realizar um planejamento participativo da região, incorporando o conhecimento dos seus moradores e usuários para chegar a uma proposta mais adequada à realidade local. Este conhecimento encontrava-se qualificado pela experiência que a comunidade adquiriu através do OP, mas não era suficiente. Também já havia um 


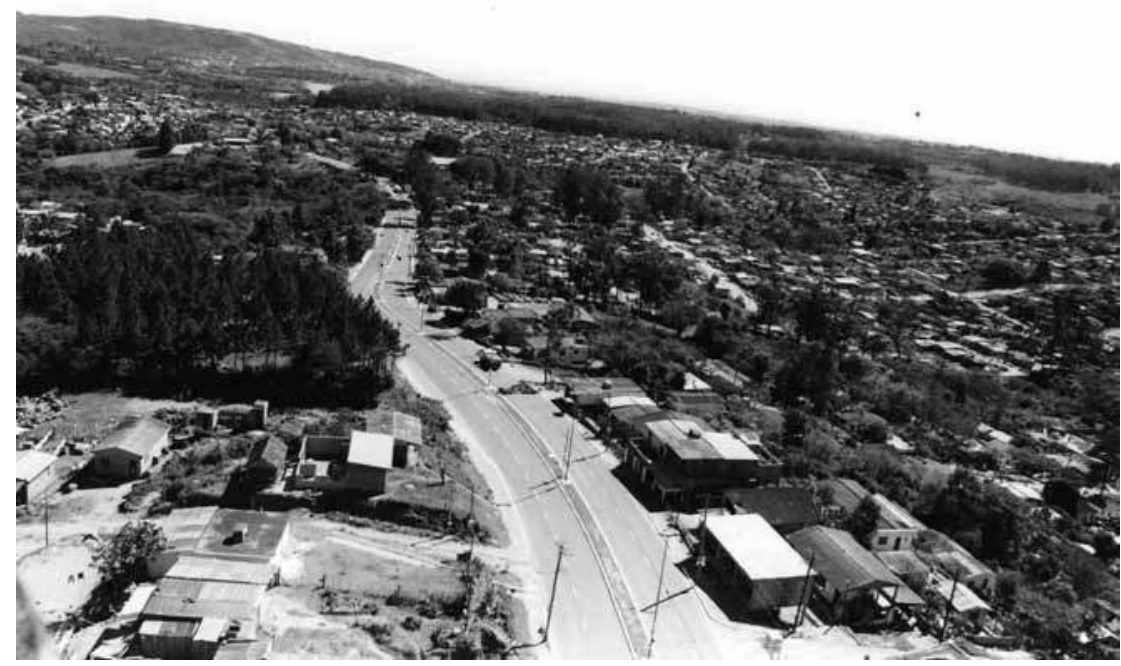

Via do Trabalhador - Eixo principal da região e ligação metropolitana

conjunto expressivo de lideranças comunitárias atuantes no sistema do OP, que servira de base inicial para a constituição do antes referido Grupo de Planejamento Local.

Nas fases de diagnóstico e análise dos conflitos existentes na região, a colaboração entre as diferentes instâncias participativas ocorreu de maneira adequada, pois os produtos gerados pelas avaliações subsidiaram ambos os processos: o de qualificação de demandas para o Orçamento Participativo e o planejamento regional promovido pelo Projeto para o desenvolvimento da região. Instrumentos específicos que foram sendo acrescentados gradualmente, como visitas coletivas aos lugares da região onde eram avançadas propostas de transformação, e também as comissões de acompanhamento das obras do Orçamento Participativo, ajudaram neste percurso de alinhamento dos diferentes dispositivos de participação dos habitantes na construção de políticas públicas.

Porém, esperava-se que o planejamento tivesse, com o tempo, uma influência maior no processo do OP do que realmente teve. No entanto, com algumas exceções relacionadas à implantação de macrorredes de infraestrutura, a necessidade do atendimento de demandas pontuais ainda predominou sobre ações de impacto regional, principalmente as relacionadas com questões de alcance mais indireto, como preservação ambiental e mobilidade urbana. Outro aspecto problemático diz respeito à diferença de tempos entre os processos de planejamento e orçamento. Enquanto a 
agilidade dos poderes públicos no atendimento de demandas pontuais se mostrou eficaz, e o resultado imediatamente visível (na qualificação da rua, implantação da rede ou construção do equipamento público), o Projeto Integrado identificou ações e diretrizes de caráter geograficamente e temporalmente mais abrangente, cujo resultado se verá na melhoria da qualidade do espaço urbano na medida em que estas forem sendo implantadas, graças às contrapartidas dos novos empreendimentos, por investimentos do poder público e também pelas demandas apresentadas no OP. Este tempo amplo de implantação dos projetos imaginados pelo Plano Integrado da Lomba fez com que o interesse das comunidades se desviasse facilmente para questões de atendimento imediato.

Merece aqui também realçar o fato de que as lideranças comunitárias que atuaram nos processos participativos ao longo desta década experimental foram se alterando com o tempo. Muitos daqueles que já alcançaram um patamar de entendimento capaz de promover uma qualificação e integração maior entre o planejamento da região e estruturas de execução como o Orçamento Participativo, já deixaram de atuar nos colegiados, cedendo lugar às novas lideranças que se incorporam gradualmente no processo, normalmente motivadas pelas demandas pontuais de suas comunidades. Estas últimas nem sempre incorporam as idéias concebidas nos grupos anteriores para o desenvolvimento da região e necessitam de algum tempo para desenvolver visões com horizontes de médio/longo prazo.

Neste quadro, o Projeto da Lomba resulta ainda em fase experimental, apesar dos anos passados desde a sua abertura. De fato, é claro que existe um enorme potencial ainda a ser desfrutado para alavancar o desenvolvimento da Lomba do Pinheiro, utilizando as experiências acumuladas nos processos que já ocorrem na região, tanto através do OP quanto pelo Projeto Integrado, na perspectiva de uma articulação maior entre estes. No entanto, os atores envolvidos verificam uma perda de uma parte deste potencial, que decorre em grande parte da falta de continuidade na implantação das diretrizes elaboradas para a região através do Projeto Integrado. É, de toda forma, importante destacar que a experiência do OP, quanto à sua forma de articulação regional, tem servido de exemplo para a criação de novos canais de interlocução entre o planejamento e a comunidade, potencializando e qualificando a relação e o grau de participação efetiva e legítima de seus cidadãos, não só na definição de alternativas para a região, como para a cidade, através da discussão e deliberação de políticas globais.

A mudança de administração em 2004 trouxe novas prioridades para a cidade, nem sempre coincidentes com as anteriores, embora os novos objetivos do programa de "Governança Solidária” (Busatto e Vargas, 2005) 
contassem com a construção de um amplo leque de ações de parceria entre o setor público, o privado e as comunidades assentadas no território portoalegrense. Há hoje necessidade de detalhar as diretrizes e propostas construídas ao longo da última década, a ponto de elaborar projetos executivos que possam ser implantados no território. Para este fim, será necessário utilizar recursos novos, e não apenas os procedentes do OP que, nos últimos anos, parecem ter reduzido o seu impacto concreto.

\section{Conclusões}

Entendendo o planejamento como um processo em que as etapas vão se ajustando na medida dos recursos humanos e financeiros, pode-se afirmar que o caminho para o futuro da Lomba do Pinheiro está bem traçado.

Hoje existe um Programa Básico de Ocupação dotado de eixos de transformação urbana bem definidos, por um lado com estímulos à ocupação e uso do solo de acordo com um claro zoneamento e, por outro, com a definição de setores prioritários de atuação. A promoção de um contínuo monitoramento do adensamento pode ajudar a atingir o patamar de qualidade necessário para o conforto da população presente e futura, desde que a comunidade local tenha condições de motivar-se e de ir assumindo progressivamente as suas próprias soluções.

A avaliação realizada até hoje na Lomba possibilita uma referência para que se estabeleçam metas de transformações urbanísticas necessárias, através do Plano de Melhorias Urbanas, nomeadamente no que tange a suprir as carências quanto ao traçado viário estruturador, necessárias para uma adequada circulação de veículos na região, assim como a prover os atuais e futuros moradores de equipamentos urbanos e comunitários.

Ações com alto nível experimental de inovação têm sido desenhadas desde 2000, como a recuperação dos assentamentos de habitação espontânea na área chamada Recreio da Divisa, um terreno de ocupação na parte íngreme de um morro que marca a separação entre Porto Alegre e outros municípios da região metropolitana. ${ }^{13}$ Aqui, não apenas as operações de remoção das famílias que ocupavam áreas de maior risco e a gradual realocação em lotes próximos se deu através de um acompanhamento feito

\footnotetext{
${ }_{13}$ As 611 famílias que tinham ocupado a área a partir do início dos anos 90 obtiveram no Orçamento Participativo do 2000 recursos para levantamento social e topográfico, depois de um intercâmbio de terrenos entre o DEMHAB (Departamento de Habitação da Prefeitura) e a empresa Guerino. A área foi declarada como Área Especial de Interesse Social (AEIS 3) e comissões populares nomeadas pelos residentes dos três diferentes sectores de risco uniram-se à equipe municipal do Projeto Integrado. Desde logo, o Grupo definiu a necessidade de remover 120 famílias em forte risco e apontou uma área próxima onde elas poderiam residir; já no OP de 2002 foram obtidos novos recursos para a infraestruturação primária.
} 
por comissões locais de moradores (Allegretti, 2005), mas uma batalha auto-organizada pelos habitantes logrou recursos públicos oriundos do OP para a regularização gradual do assentamento. Além disso, desde 2002 vários cursos de formação integraram no projeto o tema da geração de renda, desencadeando a construção de cooperativas e microempresas que trabalham sobre produções biológicas, ervas medicinais e tijolos reciclados. Infelizmente, nem todas as ações-piloto localizadas lograram ter um impacto mais amplo, por exemplo na valorização econômica do parque Saint'Hilaire, uma área de proteção natural de 940 hectares localizada na Região da Lomba.

Nesta situação de desenvolvimento incompleto das potencialidades identificadas pelos diagnósticos realizados ao longo dos anos, o percurso aponta para uma mudança de postura técnica e política iniciada no princípio do milênio com a criação de um Grupo de Trabalho; mas até o momento o poder local não sinalizou para sua continuidade.

Esta atitude de apatia e paralisia por parte da Prefeitura põe em risco toda a sensibilização e capacitação dos agentes envolvidos já realizada e gera frustração nos atores sociais, além de facilitar o desperdício dos recursos investidos e de tornar inócua a ação de planejamento integrado desenvolvida anteriormente. O risco de uma visível desmobilização da comunidade e o descrédito dos empresários e proprietários de terra já vão desenhando um horizonte próximo. Soma-se a esta possibilidade a perda de entusiasmo dos próprios técnicos municipais, que tinham logrado dar forma a um grupo interdisciplinar motivado e competente.

A continuidade das ações, que corresponde à implementação da lei do PDDUA, deve estabelecer os caminhos para viabilizar alternativas de solução, sem impor propostas. Seria importante hoje que as novas instituições políticas que estão à frente da Prefeitura escutassem os participantes e colaboradores do projeto, incluindo as demandas oriundas deste debate no próprio horizonte de atuação dos próximos anos. Nesta etapa é fundamental que os profissionais estejam preparados para prestar esclarecimentos, detalhar e explicar tecnicamente, além de agir como facilitadores para as melhorias a serem inseridas no ambiente urbano. Assim, a população beneficiária desta região poderá atuar no futuro como agente iniciador de políticas e ações e não apenas como receptor de decisões externas, tomando como base a proposição de um "Desenho Urbano" a ser aplicado no território com medidas de curto, médio e longo prazo.

Cabe aqui salientar que a recente proposta de instituir uma Lei de Operação Urbana Consorciada na região conhecida por Lomba do Pinheiro, em vigor desde 2009, visou justamente o fortalecimento das parcerias, para 
prover a região de um Plano de Melhorias Urbanas que representassem as contrapartidas que visam minimizar as carências de infraestrutura e equipamentos urbanos e comunitários, bem como recuperar o ambiente degradado e ameaçado.

Tal proposta resultou de um amplo debate em torno dos conflitos existentes, que buscou soluções compatibilizadas com os interesses dos proprietários e dos moradores da área, mas necessita de uma aposta na inovação de gestão pública, de forma a que o poder público assuma um papel proativo para "negociar" a aprovação de empreendimentos e não para decidir unilateralmente, conforme foi acontecendo nos últimos anos. Para dar um futuro a um projeto que apostou desde o início no papel central dos cidadãos na construção das decisões, manter formas colegiadas de atuação torna-se um imperativo.

Somente por esta via poderá se avançar na descentralização de políticas ambientais na Lomba através de um planejamento estratégico que concilie os diferentes interesses, com ênfase na promoção de mudança nos padrões de produção e consumo do ambiente local, capacitando as pessoas para formas solidárias e cooperativas de geração de trabalho e renda. Se não for assim, o projeto-piloto da Lomba terá dificuldade em sair do seu experimentalismo e em contagiar a cidade com os métodos e as idéias que o Projeto Integrado tem vindo a desenvolver nos últimos doze anos.

\section{Referências bibliográficas}

AA.VV. (1998), A necessária releitura da cidade. Porto Alegre: PMPA.

Allegretti, Giovanni (2002), "L'abitare come valore urbano nel nuovo piano 'esperienziale' di Porto Alegre (Brasile)", Urbanistica, 119.

Allegretti, Giovanni (2005), Porto Alegre: una biografia territoriale. Ricercando la qualità urbana a partire dal patrimonio sociale. Firenze: Firenze University Press.

Busatto, C.; Vargas, P. Zalewski (2005), Governança solidária local: fundamentos políticos da mudança em Porto Alegre. Porto Alegre: PMPA.

Comas Dias, C. E. (1993), "Plano Diretor de Porto Alegre: alguns acertos e muitas dúvidas", in W. Panizzi e J. Rovatti (orgs.), Estudos Urbanos. Porto Alegre: Editora da Universidade.

Damásio, C. (2006) (org.), Urbanizador social: da informalidade à parceria. Cambridge: Lincoln Institute of Land Policy.

Fedozzi, L. (2000), O poder da aldeia. Gênese e história do Orçamento Participativo de Porto Alegre. Porto Alegre: Tomo Editorial.

Krafta, R. (1993), "Os (maduros?) frutos da crise”, in W. Panizzi e J. Rovatti (orgs.), Estudos Urbanos. Porto Alegre: Editora da Universidade. 
Liedke, E. D., Ferretti Brum, R. (1993), "O primeiro Plano Diretor de Desenvolvimento Urbano de Porto Alegre”, in W. Panizzi e J. Rovatti (orgs.), Estudos Urbanos. Porto Alegre: Ediora da Universidade.

Oliveira, N., Barcellos, T. (1993), O conselho municipal do Plano Diretor de Desenvolvimento Urbano de Porto Alegre: a participação popular no contexto da reforma urbana, in W. Panizzi e J. Rovatti, (orgs.), Estudos Urbanos. Porto Alegre: Editora da Universidade.

Rojas, E. (2009) (org.), Construir ciudades: mejoramiento de barrios y calidad de vida urbana. Montevideo: Banco Interamericano de Desarrollo.

Silva, E. (1993), "Porto Alegre: considerações sobre a produção da paisagem urbana", in W. Panizzi e J. Rovatti (orgs.), Estudos Urbanos. Porto Alegre: Editora da Universidade. 